Bull. Mater. Sci., Vol. 3, Number 1, February 1981, pp. 29-36. (C) Printed in India.

\title{
Densities, microhardnesses and electron microscopic studies of As-Se glasses*
}

\author{
R MOHAN, T S PANCHAPAGESAN ${ }^{\dagger}$ and $\mathrm{K} \mathbf{J}$ RAO \\ Solid State and Structural Chemistry Unit, Indian Institute of Science, \\ Bangalore 560 012, India \\ $\dagger$ Materials Research Laboratory
}

MS received 27 October 1980

\begin{abstract}
Densities and microhardnesses of As-Se glasses have been measured over a wide range of composition. Anomalous variations of densities and microhardnesses have been noted. It has been found possible to explain the variation on the basis of chemical ordering in these glasses. Scanning electron microscopy has been used to investigate the nature of etching in various compositions. The chemical stabilities of these glasses towards etchants also seem to support chemical ordering in them.
\end{abstract}

Keywords. As-Se glasses ; density ; microhardness ; scanning electron microscopy.

\section{Intraduction}

As-Se glasses have been widely investigated in the literature (Kolomiets 1964; Myuller 1971; Hulls and McMillan 1974; Hurst and Davis 1974; Webber and Savage 1976). The composition dependence of properties like glass transition, electrical conductivity, etc. (Mohan et al 1980; Rao and Mohan 1980) exhibit anomalous variations as a function of composition. Such variations can, however, be fairly well understood from a chemically ordered network model (Betts et al 1970; Lucovsky et al 1974; Lucovsky et al 1977). In order to further explore the implications of a chemically ordered network model for As-Se glasses we have studied variations of densities and microhardnesses of these glasses over a wide range of compositions. Further, in chemically ordered As-Se glasses we expect the presence of Se-Se and As-As bonds exclusively on one side of $\mathrm{As}_{2} \mathrm{Se}_{3}$ composition. It would therefore be interesting to investigate the stability of these glasses towards chemical attack. We report in this paper a scanning electron microscopic examination on the nature of chemical attack by two powerful etchants namely, aqua-regia and hydrofluoric acid on these glasses. These studies also seem to imply the validity of chemical ordering model.

\footnotetext{
* Communication No. 95 from Solid State and Structural Chemistry Unit.
} 


\section{Experimental}

As-Se glasses were prepared from 5 nine-purity elemental arsenic and selenium obtained from Koch-Light Co., UK. The method of preparation has been described elsewhere (Mohan et al 1980). Density measurements were made on these glasses by Archimedes method using double distilled water at room temperature. The measurements were repeated several times for consistent accuracy in the measurements. The density is accurate to $\pm 0.001 \mathrm{~g} \mathrm{~cm}^{-3}$.

Microhardnesses were determined by Vicker's diamond indentation method. Glass specimens with plane parallel faces were obtained for these measurements by lapping and polishing with rouge powder. A load of $50 \mathrm{~g}$ was used on each glass for indentation. The reported microhardnesses are accurate to $\pm 5 \%$.

Scanning electron microscopic studies were performed using a Cambridge Stereoscan-150 electron microscope. The specimens for examination were first polished using rouge powder. Glasses were then subjected to chemical attack by aquaregia or hydrofluoric acid for a fixed period of time. After etching the glasses were thoroughly washed in distilled water and dried. Since these glasses are nonconducting, they were coated with $150-200 \AA$ thick gold-palladium alloy film using a polaron sputter coater before scanning their surfaces in the electron microscope.

\section{Results and discussion}

It was found to be extremely difficult to obtain glasses beyond $60 \%$ As $\left(\mathrm{As}_{60} \mathrm{Se}_{40}\right)$. The glassy nature of various compositions were confirmed both from $x$-ray diffraction patterns and from differential scanning calorimetric runs (occurrence of glass transition temperature followed by crystallization peaks). The densities of glasses are shown as a function of composition in figure 1. The density of pure arsenic glass reported in the literature (Greaves et al 1979) is also shown in figure 1. Other reported density values have been included in the figure for comparison (Myuller 1971). $\mathrm{As}_{40} \mathrm{Se}_{60}$ composition corresponds to a maximum in the densities. But this maximum is anomalous in the sense that the densities of these glasses do not extrapolate to the correct value of the density of glassy arsenic (figure 1). The increase in density with incorporation of more and more arsenic in the selenium rich glasses is possibly due to (a) enhanced cross-linking and (b) degradation of selenium chain fragments. This results in more efficient packing of the constituent atoms. Beyond $\mathrm{As}_{40} \mathrm{Se}_{60}$ composition, occurrence of As-As linkages will only produce steric hindrance for efficient packing unless we assume that there is a very large concentration of broken bonds. In covalently bonded and chemically ordered As-Se glasses, we expect the concentration of broken bonds to be very much smaller than is required to give rise to such high densities. Therefore the density of glass decreases with further increase in arsenic concentration beyond the stoichiometric composition $\mathrm{As}_{40} \mathrm{Se}_{60}$. It is perhaps because of this reason that beyond $\mathrm{As}_{60} \mathrm{Se}_{40}$ the system prefers to phase separate and glasses are extremely difficult to prepare.

The microhardnesses of As-Se glasses as a function of composition are shown in figure 2. Here again the trend appears to be very similar to that of densities in figure 1. Reported microhardness values (Myuller 1971; Webber and 


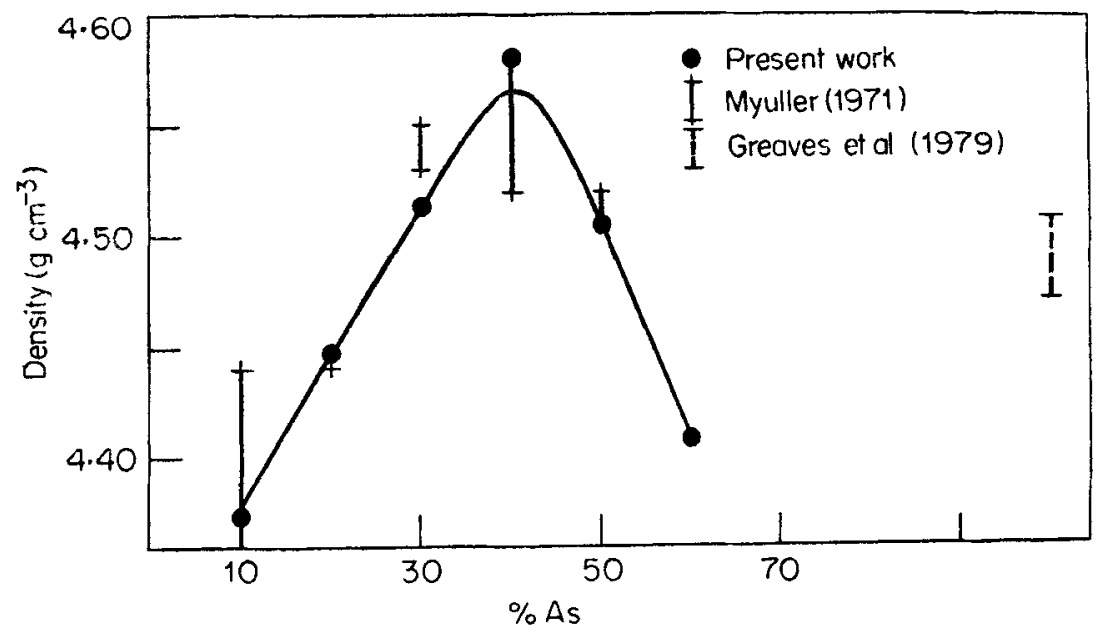

Figure 1. Variation of densities as a function of composition.

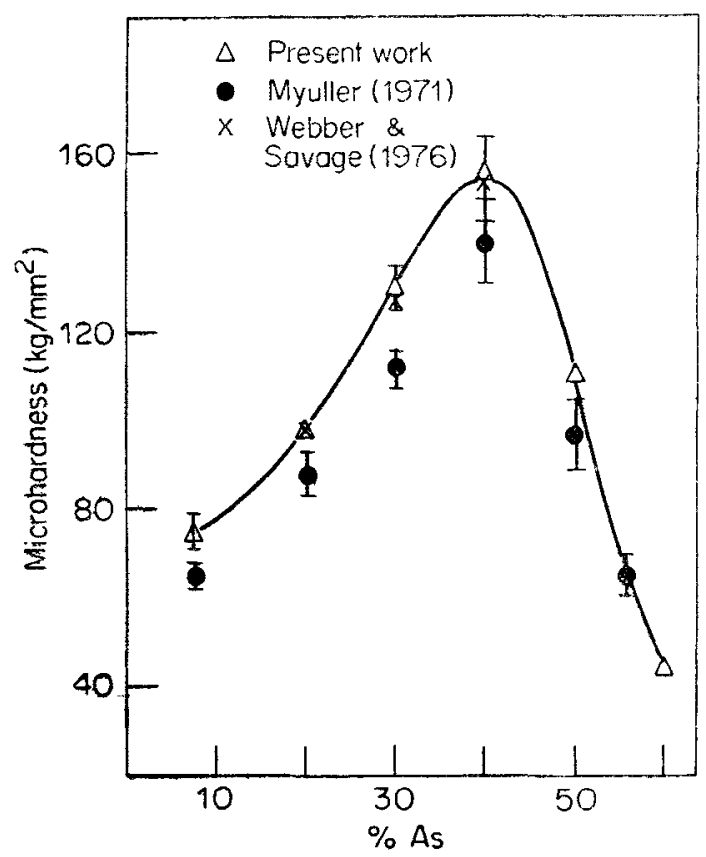

Figure 2. Variation of microhardnesses as a function of composition.

Savage 1976) for some of the compositions are also indicated in figure 2. Microhardness is a property which is difficult to define clearly but is widely used in characterising many types of glasses. The indentation processes in microhardness measurements is generally believed to involve one or all of the following processes: (i) a permanent densification, (ii) plastic flow and (iii) breaking of bonds. Permanent densification has usually a negligible effect in microhardness measurements. 
Also these glasses have been found to be vary brittle. Hence, we ignore the first two effects and assume that breaking of bonds is the only important factor which determines the microhardnesses of these glasses. We therefore expect that microhardness to be a monotonic function of bond energy. In figure $3 a$ a plot of microhardness $v s$ average bond energy (average bond energy has been evaluated as the total cohesive energy divided by the total number of bonds assuming a chemically ordered network of fully valence saturated atoms) is given. With the exception of $\mathrm{As}_{60} \mathrm{Se}_{40}$ glass, microhardness of other glasses seem to be quite linear with the average bond energy.

Microhardness is dimensionally equivalent to elastic moduli and it would be reasonable to expect a relation between microhardness and elastic moduli of the material and indeed such relations for glasses have been discussed in the literature (Sakka and Mackenzie 1971; Yamane and Mackenzie 1974). In the case of ionic materials where interaction potential is of Born-Lande or Born-Mayer type, it is possible to show that bulk modulus $K$ is approximately equal to specific cohesive energy (Born and Huang 1966). For example if

$$
\begin{aligned}
& U=-(A / r)+\left(B / r^{n}\right), \\
& 1 / \beta=K=-v(d p / d v)=A / 9 v_{0} r_{0}(-1+n),
\end{aligned}
$$

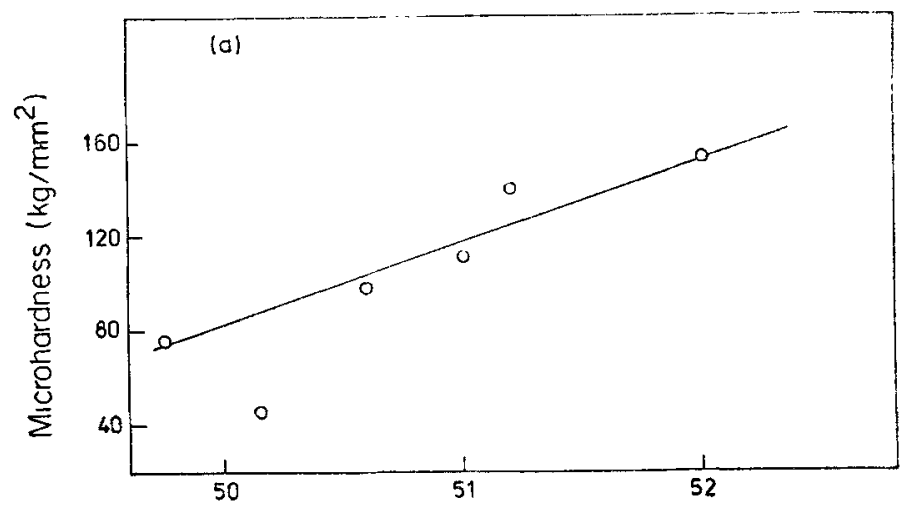

Average bond energy ( $\mathrm{kcal} / \mathrm{mole})$

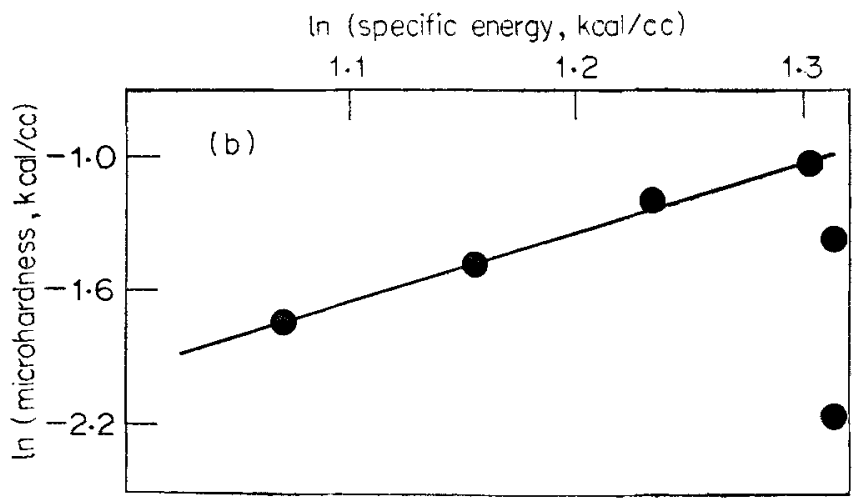

Figure 3. a. Variation of microhardnesses as a function of average bond energy and b. Log-log plot of microhardness vs specific energy. 

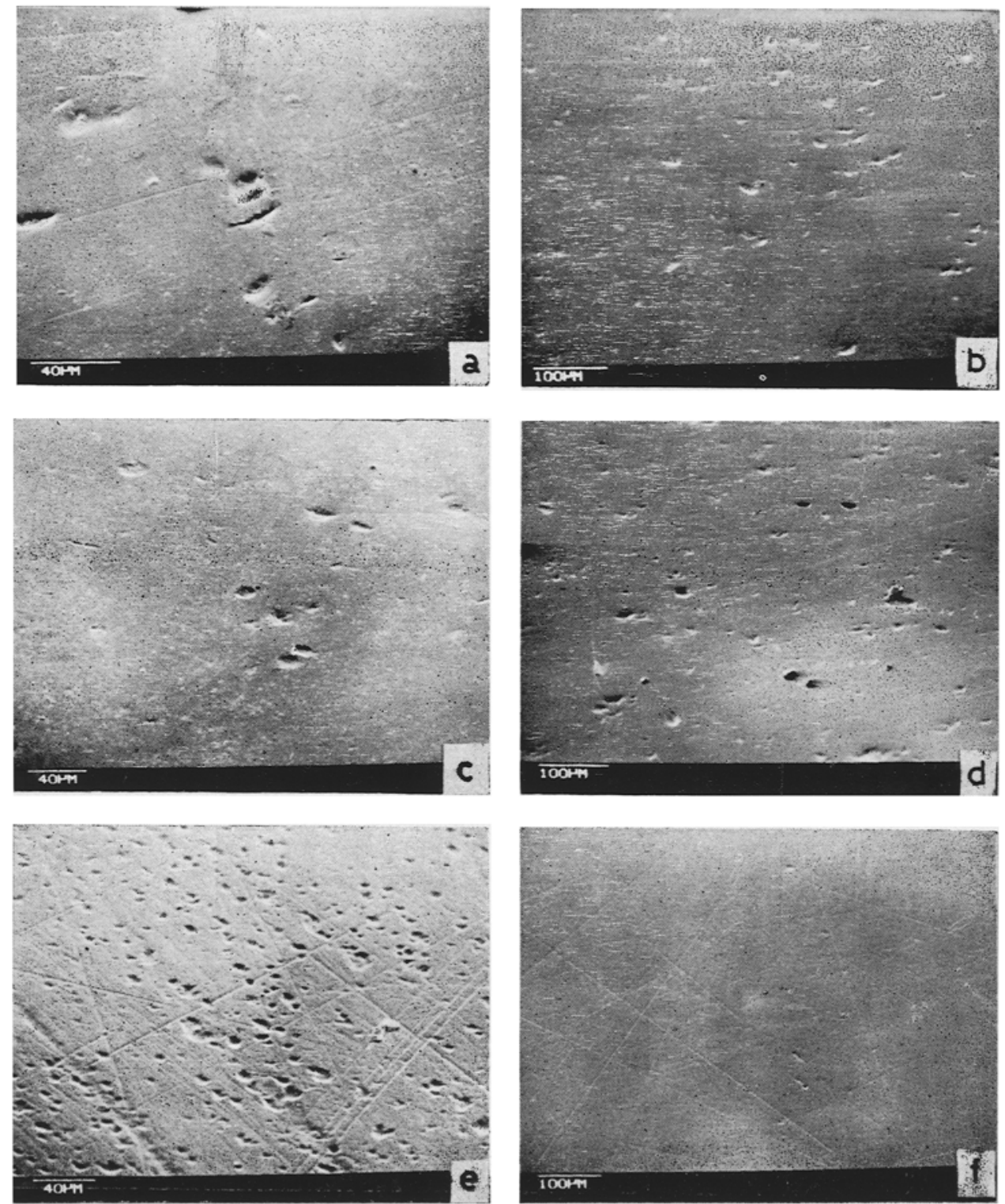

Figure 4. SEM micrographs of etched As-Se glasses. a, b. $\mathrm{As}_{30} \mathrm{Se}_{20} ; \mathrm{c}, \mathrm{d}$. $\mathrm{As}_{10} \mathrm{Se}_{00} ;$ e, f. $\mathrm{As}_{00} \mathrm{Se}_{40}$; a, $\mathrm{c}$ and $\mathrm{e}$ were etched in aqua-regia for 10 minutes; $b, d$ and $f$ were etched in hydrofluoric acid for 15 minutes. 

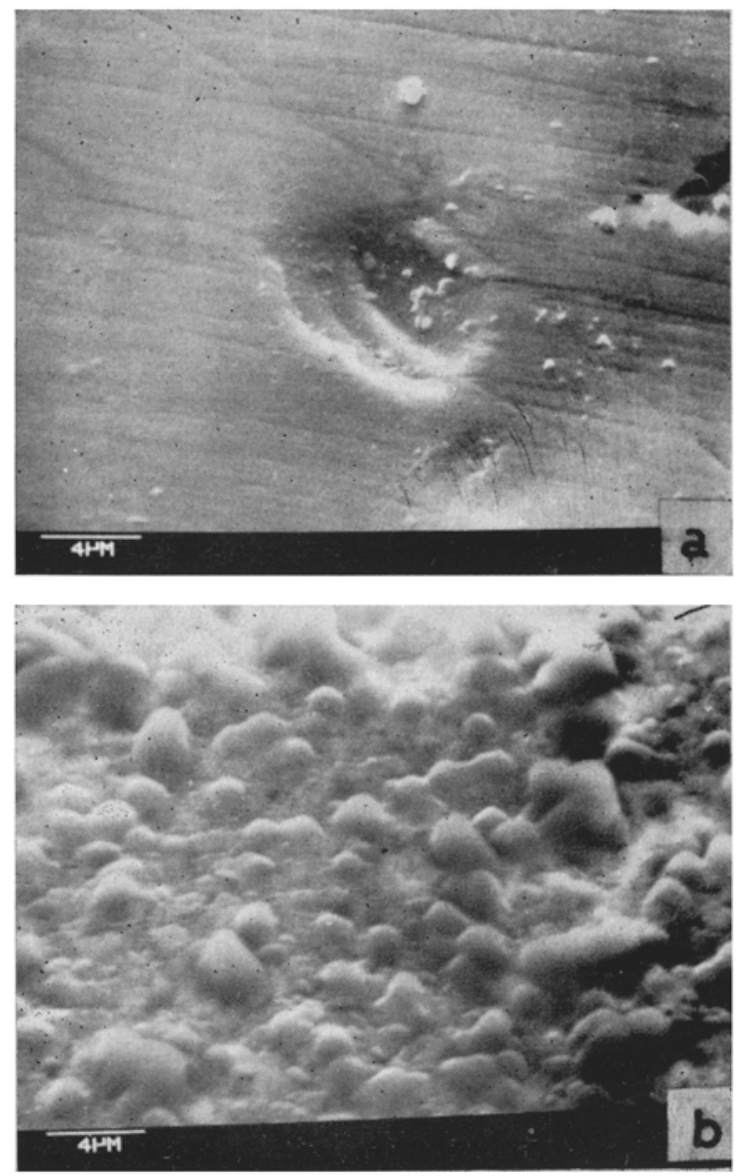

Figure 5. SEM micrographs of etched a. $\mathrm{As}_{30} \mathrm{Se}_{70}$ glass in hydrofluoric acid ( $35 \mathrm{~min}$ ) and b. $\mathrm{As}_{60} \mathrm{Se}_{40}$ glass in aqua-regia $(21 \mathrm{~min})$ at higher magnifications. 
which indicates that for $n \sim 9$

$$
K \simeq U / v_{0}
$$

(using the equilibrium relation $A / r_{0}=n B / r_{0}^{n}$ ).

In the above expression, $v_{0}$ is the volume of a pair of ions. Hence bulk modulus can be considered to be approximately equal to the sperific cohesive energy of the material. If we assume that this relation is approximately true for covalently bonded materials also, we should expect microhardness and specific cohesive energy to be functionally related. In figure $3 \mathrm{~b} \log -\log$ plot of microhardness expressed in

$$
\mathrm{kcal} / \mathrm{cm}^{3}\left(\frac{H_{b} \times 10^{3}}{10^{-2} \mathrm{~cm}^{2}} \times \frac{980 \mathrm{~cm}}{\mathrm{sec}^{2}} \times \frac{\mathrm{cm}}{\mathrm{cm}} \times \frac{1 \mathrm{kcals}}{4.186 \times 10^{10} \mathrm{ergs}}\right)
$$

(where $H$ is the microhardness in $\mathrm{kg} / \mathrm{mm}^{2}$ )

$v s$ specific cohesive energy is given. Arsenic-rich glasses do not seem to fall in line with selenium-rich glasses. In glass compositions up to $\mathrm{As}_{40} \mathrm{Se}_{60}$ the slope indicates that microhardness is a high power function of the specific energy and hence of the elastic moduli. However, the relation between microhardness and cohesive energy shown in figure $3 \mathrm{a}$ reflects the general validity of a chemically ordered network model.

In figure 4 are shown the scanning electron micrographs of $\mathrm{As}_{30} \mathrm{Se}_{70}, \mathrm{As}_{40} \mathrm{Se}_{80}$ and $\mathrm{As}_{60} \mathrm{Se}_{40}$ samples which were etched in aqua-regia and hydrofluoric acid. These samples were taken from a single batch of glasses and etched for equal lengths of time and the micrographs correspond to identical magnification. The following observations can be made. Arsenic-rich glasses are readily etched by aqua-regia, which is known to be a powerful oxidising agent. The rate of ' tching of arsenic rich glass in hydrofluoric acid is negligible in comparison. The seleniumrich glasses are more prone to attack by hydrofluoric acid than by aqua-regia. $\mathrm{As}_{40} \mathrm{Se}_{80}$ composition is somewhat midway between in its behaviour. In figure 5, the nature of pits formed are shown at higher magnifications for two samples, $\mathrm{As}_{80} \mathrm{Se}_{40}$ etched in aqua-regia and $\mathrm{As}_{30} \mathrm{Se}_{70}$ etched in hydrofluoric acid. The photographs reveal that the attack of aqua-regia on arsenic-rich glass is quite severe while that of hydrofluoric acid on selenium-rich glass is slow and retarded.

If these glasses corresponded to a random network, we would have expected no such drastic changes in chemical stability towards the etchant. Though more detailed structural work is necessary to establish the nature of etching action, we would like to point out that such profound changes in etching behaviour is likely to be a consequence of chemical ordering. It is only in arsenic-rich compositions that As-As bonds are formed and it is well-known that arsenic is readily oxidised to $\mathrm{As}_{2} \mathrm{O}_{3}$ (Fritzsche 1973). The etching process is likely to involve oxidation of As followed by dissolution of $\mathrm{As}_{2} \mathrm{O}_{3}$.

Thus the apparently anomalous variation of physical properties of As-Se glasses is directly related to the nature of chemical ordering in these glasses.

\section{Acknowledgements}

We thank Professor C N R Rao, Solid State and Structural Chemistry Unit, Indian Institute of Science, for his kind encouragement. We are also thankful 
to the Department of Science and Technology, Government of India, for financial support.

\section{Reforences}

Betts F, Bienenstock A and Ovshinsky S R $1970 \mathrm{~J}$. Non-Cryst. Solids 4354

Born $M$ and Huang $K 1966$ in Dynamical theory of crystal lattices (London : Oxford University Press) pp. 25.

Fritzsche $\mathrm{H} 1973$ in Electronic and structural properties of amorphous semiconductors Ed. PG LeComber and $J$ Mort (London and New York : Academic Press) pp. 582

Greaves G N, Elliott S R and Davis E A 1979 Adv. Phys. 2849

Hulls K and McMillan P W 1974 J. Non-Cryst. Solids 15357

Hurst C H and Davis E A 1974 J. Non-Cryst. Solids 16343

Kolomiets B T 1964 Phys. Status Solidi 7359

Lucovsky G, Galeener F L, Keezer R C, Geils R H and Six H A 1974 Phys. Rev. B10 5134

Lucovsky G, Galeener F L, Geils R H and Keezer R C 1977 In The structure of non-crystalline materials ed. P H Gaskell (London: Taylor and Francis) pp. 127

Mohan R, Sudha Mahadevan and Rao K J 1980 Mater. Res. Bull. 15917

Myuller R L 1971 In Electrical conductivity of vitreous substances (New York : Consultant Bureau) pp. 135

Rao K J and Mohan R 1980 J. Phys. Chem. 841917

Sakka S and Mackenzie J D 1971 J. Non-Cryst. Solids 6145

Webber P J and Savage J A 1976 J. Non-Cryst. Solids 20271

Yamane M and Mackenzie J D 1974 J. Non-Cryst. Solids 15153 